\title{
Evaluation of Code Blue Implementation and Its Outcomes in Pediatric Patients
}

öz

Amaç: Mavi kod, hastane içinde acil müdahale gerektiren durumlarda en kısa zamanda olay yerine ulaşılmasını ve etkin müdahalenin yapılmasını sağlayan, evrensel acil durum kodudur. Bu çalışmanın amacı, hastanemizde çocuk hastalarda uygulanan mavi kod bildirimleri ve içeriklerini değerlendirmek, uygulamaya dikkat çekmek ve uygulamanın hasta güvenliğini açısından önemini vurgulamaktır. Yöntem: Acıbadem Mehmet Ali Aydınlar Üniversitesi Artakent hastanesinde Ocak 2017-Ağustos 2019 tarihleri arasında çocuk hastalar için tutulan tüm mavi kod formları retrospektif olarak incelendi. Hastaların demografik ve tıbbi bilgileri, mavi kod çağrılarının verilme nedeni, ekibin olay yerine ulaşma süresi, yapılan tüm müdahale ve uygulamalar kaydedildi.

Bulgular: Çalışma süresince toplam 70 pediyatrik mavi kod çağrısı yapıldı. Mavi kod verilen hastaların 45'i (\%64.3) erkek, 25'i (\%35.7) kızdı. Hastaların yaş ortalaması $38.3 \pm 14.2$ aydı. Olay yerine ulaşma süresi ortalama $2.02 \pm 0.92 \mathrm{dk}$. idi. Verilen çağrıların 36 'sı (\%51.4) çocuk servisinden, 23'ü (\%32.9) acil servisten, 7'si (\%10) çocuk polikliniğinden, 2'si (\%2.9) hastane giriş alanından, 1'i (\%1.4) fizik tedavi ve rehabilitasyon polikliniğinden, 1'i (\%1.4) radyoloji biriminden verilmişti. Çağrıların \%64.3'ü mesai saatleri içinde, \%35.7'si sorumlu hekim, \%50'si hemşire ve \%14.3'ü yardımcı sağlık personeli tarafından verilmişti. Hastaların \%35.7'si entübe edildi, \%27.1'ine kardiyopulmoner resüsitasyon (KPR) uygulandı. Hastaların \%64.3'ü yoğun bakım ünitesine yatırıldı. Diğer hastaların takip ve tedavilerine bulundukları serviste veya acil serviste devam edildi. KPR uygulanan hastaların \%68.4'ü hastaneden taburcu edildi. Sonuç: Mavi kod ekibinde etkin ve alanında deneyimli uzmanların olması, hastane içi eğitimlere gereken önemin verilmesi, verilen eğitimler ile kardiyopulmoner arrestlerin hızlı tanınması hastaların sağ kalım oranlarını arttırmaktadır. Çocuk hasta kayıtlarının ayrı olarak değerlendirildiği çalıșmamızda mavi kod sisteminin hedeflenen süre açısından standartlara uygun ve başarılı bir şekilde uygulandığı görülmektedir.

Anahtar kelimeler: Mavi kod, çocuk yoğun bakım, kardiyopulmoner arrest, kardiyopulmoner resüsitasyon

\section{ABSTRACT}

Objective: Code Blue is a universal emergency code, ensuring rapid arrival at the scene of the event and implementation of effective intervention for in-patients requiring emergency medical intervention The aim of our study is to evaluate Code Blue, and its contents applied for pediatric cases in our hospital, draw attention to its implementation and emphasize the importance of its application with respect to patient's safety.

Methods: All Code Blue forms applied for pediatric patients at a Acıbadem Mehmet Ali Aydınlar University, Artakent hospital between January 2017 and August 2019, were evaluated retrospectively. Demographic and medical information of cases, reasons for Code Blue alerts, arrival time of the Code Blue Response Team at the scene, all medical interventions and practices performed at the scene were recorded.

Results: During the study period 70 pediatric Code Blue calls were made. Among Code Blue patients, 45 cases (64.3\%) were male, 25 cases (35.7\%) were female. Mean age of the patients was $38.3 \pm 14.2$ months. Mean arrival time of the code blue team burst on the scene was $2.02 \pm 0.91$ minutes. The code blue calls were made most commonly from general pediatric wards $(n=36 ; 51.4 \%)$ followed by emergency room (ER) ( $n=23 ; 32.9 \%)$, pediatric polyclinics ( $n=7 ; 10 \%)$, hospital entrance $(n=2 ; 2.9 \%)$, physical therapy and rehabilitation polyclinic, radiology department ( $n=1 ; 1.4 \%$ for each). Majority of codes (64.3\%) were given during work hours. Physicians-in-charge (35.7\%), nurses (50\%) and other healthcare personnel (14.3\%) activated the Code Blue. A total of $35.7 \%$ of patients were intubated, and $27.1 \%$ of them required cardiopulmonary resuscitation (CPR). The $64.3 \%$ of the patients were hospitalized in the pediatric intensive care unit. The rest of the patients continued to receive medical treatment in their respective wards or in the ER. The $68.4 \%$ of patients who had received CPR were discharged. Conclusion: The presence of competent, and experienced specialists in the Code Blue team, giving due importance to in-hospital training, and rapid recognition of cases with cardiopulmonary thanks to training offered increase survival rates of patients. In our study where records of pediatric patient were evaluated separately, it is seen that Code Blue system is implemented in compliance with the standards and successfully, particularly in terms of targeted time interval.

Keywords: Code blue, pediatric intensive care, cardiopulmonary arrest, cardiopulmonary resuscitation
Received: 07 November 2019

Accepted: 07 January 2020

Online First: 31 January 2020

Cite as: Sık G, Çıtak A. Çocuk hastalarda mavi kod uygulaması ve sonuçlarının değerlendirilmesi. JARSS 2020;28(1):47-51.

Güntülü Şık

Acıbadem Mehmet Ali Aydınlar Üniversitesi Tıp Fakültesi, Çocuk Yoğun Bakım Bilim Dalı, İstanbul - Türkiye drguntulu@hotmail.com ORCID: 0000-0002-4526-0485

A. Çıtak 0000-0002-5108-3913 Acıbadem Mehmet Ali Aydınlar Üniversitesi Tıp Fakültesi, Çocuk Yoğun Bakım Bilim Dalı, Istanbul, Türkiye 


\section{Giriş}

Mavi kod, hastane içinde kardiyopulmoner veya solunum arresti gibi acil müdahale gerektiren durumlarda, en kısa zamanda olay yerine ulaşan profesyonel bir ekip tarafından etkin müdahalenin yapıldığı, evrensel acil durum kodudur. Acil tıbbi müdahaleye gereksinim duyan hastalar, hasta yakınları ve hastane personeline en kısa sürede müdahale edilmesini sağlar. Böylece hastane içi kardiyopulmoner arrestler hızlı bir şekilde tanınıp müdahale edilerek mortalitede azalma, morbiditede iyileşme sağlanabilir. Bu sistemde tüm dünyada aynı renk kullanılmaktadır. Mavi kod süreci için teknolojik çağrı sisteminin ve eğitimli ekibin oluşturulması, ekibin ve ekipmanın hazır ve donanımlı olarak tutulması, etkin müdahale, doğru olay yönetimi ve tutulan kayıtlar önemlidir ${ }^{(1,2)}$.

Mavi kod ekibi; kardiyopulmoner resüsitasyon konusunda deneyimli ve eğitimli uzman hekim ve hemşirelerden oluşur. Ekip en kısa sürede çağrının verildiğ birime ulaşmayı ve etkin kardiyopulmoner resüsitasyonu yapmayı amaçlar. Çağrı başlangııından bitimine kadar geçen sürede hasta ile ilgili tüm bilgiler, hastaya ait vital bulgular, uygulanan işlem ve tedaviler ile olayın sonlanım şekli mavi kod olay bildirim formuna kaydedilir. Hastane kalite birimi tarafından bu formlar saklanır ${ }^{(1,2)}$.

Bu uygulama ilk olarak Amerika Birleşik Devletleri'nde Kansas Bethany Tıp Merkezinde kullanılmaya başlanmıştır. Ülkemizde ise 2009 yılında yayımlanan Sağlık Kurum ve Kuruluşlarında Hasta ve Çalışan Güvenliğinin Sağlanması ve Korunmasına iliş̧kin Usul ve Esaslar hakkında Tebliğ ve 2011 yılında yayımlanan Hasta ve Çalışan Güvenliği Yönetmenliği ile zorunlu hale getirilmiştir ${ }^{(1)}$. Ulusal terminolojinin ve uygulamanın genelleşmesi amacıyla Sağlık Bakanlığınca "2222" No'lu telefon aktivasyon çağrı sisteminin kullanılması uygun görülmüştür.

Erişkin hastalarda mavi kod uygulaması ile ilgili birçok çalışma olmasına rağmen, çocuk hastaların ayrı olarak değerlendirildiği çalışma ülkemizde yapılmamıştır. Bu çalışmanın amacı, hastanemizde çocuk hastalarda uygulanan mavi kod bildirimleri ve içeriklerini değerlendirmek, etkinliğini göstermek, uygulamaya dikkat çekmek ve uygulamanın önemini vurgulamaktır.

\section{GEREÇ ve YÖNTEM}

Bu çalışma 286 yataklı Acıbadem Mehmet Ali Aydınlar Üniversitesi Tıp Fakültesi Atakent Hastanesinde Ocak 2017-Ağustos 2019 tarihleri arasında yapıldı. Acıbadem Mehmet Ali Aydınlar Üniversitesi Tıbbi Araştırma Etik Kurulundan onay alındı (2019-18/5). Hastanemizde mavi kod çağrısı için 2222 No'lu telefon aktivasyon sistemi kullanılmaktadır. Çocuk hastalar için tutulan tüm mavi kod bildirim formları geriye dönük olarak incelendi. Mavi kod bildirim formlarından hastanın yaşı, cinsiyeti, çağrıyı veren kişi, çağrının verilme saati, çağrının yapıldığı birim, ekibin olay yerine ulaşma süresi, yapılan müdahale, kardiyopulmoner resüsitasyon yapılıp yapılmadığı, çağrının sonlanım şekli ve uygulama sonuçlarına ulaşıldı, bilgiler kaydedildi. Erişkin hastalar için olan veya tatbikat amaçlı verilen çağrılar çalışmaya dahil edilmedi.

\section{İstatistiksel yöntem}

Çalışmada elde edilen bulgular değerlendirilirken SPSS 21,0 paket programı (IBM SPSS Statistics for Windows, Version 21.0; IBM Corp., Armonk, New York, USA) kullanıldı, verilerin analizi de aynı program ile yapıldı. Analizde frekanslar, yüzdeler, ortalamalar ve standart sapmalar kullanıldı.

\section{BULGULAR}

Çalışma süresince toplam 70 pediatrik mavi kod çağrısı yapıldı. Mavi kod verilen hastaların 45'i (\%64.3) erkek, 25'i (\%35.7) kız idi. Hastaların yaş ortalaması $38.3 \pm 14.2$ ay olarak bulundu.

Mavi kod ekibinin olay yerine ulaşma süresi ortalama $2.02 \pm 0.92 \mathrm{dk}$ idi. Çağrılara ulaşma süreleri incelendiğinde, 22 çağrıya $1 \mathrm{dk}$ 'da, 32 çağrıya $2 \mathrm{dk}$ da, 10 çağrıya 3 dk'da, 4 çağrıya 4 dk'da, 2 çağrıya da 5 dk'da ulaşıldığı belirlendi (Şekil 1).

Verilen çağrıların 36'sı (\%51.4) çocuk servisinden, 23'ü (\%32.9) acil servisten, 7'si (\%10) çocuk polikliniğinden, 2'si (\%2.9) hastane giriş alanından, 1'i (\%1.4) fizik tedavi ve rehabilitasyon polikliniğinden, $1^{\prime} i$ (\%1.4) radyoloji biriminden verilmişti (Tablo I). Çağrıların \%64.3'ünün $(n=45)$ mesai saatleri içinde (08.00-18.00), \%35.7'sinin $(n=25)$ mesai saatleri dışında verildiği (18.00-08.00) saptandı. 


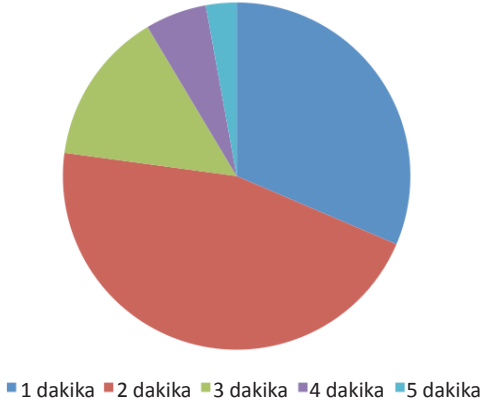

Şekil 1. Mavi kod çağrısına ulaşma süreleri.

Tablo I. Mavi kod çağrısının yapıldığı birimler

\begin{tabular}{lc}
\hline Çağrının yapıldığı birim & $\mathbf{n}(\%)$ \\
\hline Servis & $36(51.4)$ \\
Acil servis & $23(32.9)$ \\
Poliklinik & $7(10)$ \\
Hastane giriş alanı & $2(2.9)$ \\
FTR polikliniği & $1(1.4)$ \\
Radyoloji ünitesi & $1(1.4)$ \\
\hline
\end{tabular}

Çocuk servisinde veya acil serviste mavi kod çağrısı verilen hastaların en sık tanıları sistemlere göre ayrıldığında nörolojik hastalıklar ( $n=19)$, konjenital kalp hastalığı $(n=6)$, karaciğer yetersizliği $(n=6)$, alt solunum yolu enfeksiyonu $(n=5)$, hematolojik hastalıklar $(n=5)$, travma $(n=5)$, kardiyak aritmiler $(n=3)$, intrakranial kitle $(n=2)$, anafilaksi $(n=2)$ ve diğerleriydi. Çocuk polikliniğinde verilen çağrıların 4 'ünde alt solunum yolu enfeksiyonu nedeniyle gelişen solunum sıkıntısı, 2 hastada febril konvülsiyon, 1 hastada senkop vardı. Hastane giriş alanında verilen 2 çağrı hastaneye ateş şikayeti ile başvuran ve konvülsiyon geçiren hastalara aitti. Fizik Tedavi ve Rehabilitasyon (FTR) Polikliniğinden bir çağrı verilmişti. Bu hasta hidrosefali ve büyüme gelişme geriliği nedeniyle takip edilen, FTR program takibinde olan ve beslenme sonrası aspirasyon gelişen hastaydı. Radyoloji biriminden verilen çağrıda alt solunum yolu enfeksiyonu ile başvuran hastada direkt akciğer grafisi çekilirken solunum sıkıntısı gelişmişti.

Mavi kod çağrılarının nedenleri incelendiğinde, 19'unun kardiyopulmoner arrest, 14'ünün konvülsiyon, 11'nin solunum arresti, 11'inin senkop, 8'inin solunum sıkıntısı, 5'inin akut bilinç değişikliği, 2'sinin anafilaktik reaksiyon olduğu görüldü (Tablo II). Kardiyopulmoner arrestlerin en sık nedeni konjenital kalp hastalığı, hipoksik solunum yetmezliği ve ritm bozukluğuydu. Çağrıların \%35.7'si ( $n=25)$ sorumlu hekim, \%50'si ( $n=35)$ hemşire ve \%14.3'ü $(n=10)$ yardımcı sağıık personeli tarafından verilmişti.

Tablo II. Mavi kod çağrısının nedeni

\begin{tabular}{lc}
\hline Çağrının nedeni & $\mathbf{n}(\%)$ \\
\hline Kardiyopulmoner arrest & $19(27.1)$ \\
Konvülsiyon & $14(20)$ \\
Solunum arresti & $11(15.7)$ \\
Senkop & $11(15.7)$ \\
Solunum sıkıntısı & $8(11.4)$ \\
Akut bilinç değişikliği & $5(7.1)$ \\
Anafilaksi & $2(2.9)$ \\
\hline
\end{tabular}

Hastaların \%35.7'si ( $n=25)$ entübe edildi, \%27.1'ine $(n=19)$ kardiyopulmoner resüsitasyon (KPR) uygulandı. On altı (\%22.9) hastada kardiyopulmoner resüsitasyon sonrası sinüs ritmine dönüş sağlandı, ancak 3 hasta mavi kod müdahale sırasında (1 hasta konjenital kalp hastalı̆̆ı, Down sendromu ve pnömoni, 1 hasta yüksekten düşme, 1 hasta doğumsal metabolik hastalık, hipertrofik kardiyomyopati), 3 hastada yoğun bakım takibine alındıktan sonra kaybedildi ( 2 hasta yüksekten düşme, 1 hasta konjenital kalp hastalığı, doğumsal metabolik hastalık). KPR uygulanan hastaların \%68.4'ü hastaneden taburcu edildi. Mavi kod ekibi olay yerine gelene kadar hastaların \%85.7'sine ( $n=60)$ müdahale edilmişti, \%78.6'sında $(n=55)$ hava yolu açıklığı sağlanmıştı. Hastaların \%52.9'una ( $n=37)$ damar yolu açıldı, \%31.4'üne $(n=22)$ yalnızca kan basıncı, nabız, saturasyon ve kan şekeri bakıldı.

Hastaların \%64.3'ü ( $n=45$ ) Yoğun Bakım Ünitesine yatırıldı. Diğer hastaların takip ve tedavilerine bulundukları serviste veya Acil Serviste devam edildi.

\section{TARTIŞMA}

Mavi kod hastane içi kardiyopulmoner arrest durumlarında en kısa sürede müdahale yapılmasını sağlayan acil durum çağrı sistemidir. Ülkemizde Sağılı Bakanlığı tarafından hastanelerde zorunlu hale getirilen mavi kod uygulaması hasta güvenliği açısından önemli bir standarttır. Ayrıca günümüzde bu uygulama hastanelerin hizmet kalite standartlarının değerlendirilmesinde önemli bir ölçüt haline gelmiştir ${ }^{(1)}$. Etkin ve zamanında yapılan müdahalenin standardize edilmesi müdahale sonrası hastanın sağ kalım şansını arttırır. 
Mavi kod uygulamasında başarıyı etkileyen faktörlerin başında erken müdahale gelmektedir. Mavi kod ekibi ve KPR konusunda deneyimli sağlık personeli ulaşıncaya kadar temel yaşam desteğine başlanmasının sağ kalımı arttırdığı gösterilmiştir ${ }^{(2,3)}$. Amerikan Kalp Derneği (AHA) kılavuzu da kardiyopulmoner arrestte $2 \mathrm{dk}$ 'dan daha kısa sürede müdahale etmeyi hedef olarak belirlemiştir. illk $4 \mathrm{dk}$ 'da temel ve ileri yaşam desteğine başlandığını gösteren çalışmalarda sağkalım oranı artmaktadır (4-6). Ayrıca mavi kod ekibinin hastaya ulaşım süresi ile sağkalım arasında doğrudan ilişki vardır ${ }^{(5,7,8)}$. Özütürk ve ark. ${ }^{(6)}$, yaptığı çalışmada, çağrıya ortalama ulaşma süresi $1.1 \mathrm{dk}$, sağkalım \%61, Bal ve ark. ${ }^{(5)}$ yaptığı çalışmada, ortalama ulaşma süresi $2.17 \mathrm{dk}$, sağkalım \%67, Murat ve ark. ${ }^{(9)}$, yaptığı çalışmada ise ulaşma süresi $2.72 \mathrm{dk}$ ve sağkalım \%47 olarak bulunmuştur. Ancak hastaya ulaşım süresinin $4 \mathrm{dk}^{\prime}$ dan daha kısa olmasına rağmen, sağkalım oranının düşük olduğu (\%20.3) çalışmalar da bildirilmiştir ${ }^{(10)}$. Çalışmamızda, mavi kod ekibi gelmeden önce hastaların \%85.7'sine müdahale edilmişti (hava yolu açıklığının sağlanması, aspirasyon, oksijen verme, damar yolu açılması vb.). Mavi kod ekibinin ulaşma süresi $2.02 \pm 0.92 \mathrm{dk}$ 'ydı ve birçok çalışmadan daha kısa sürede olay yerine ulaşılmıştı $(9,11,12)$. Bu da mavi kod sisteminin hastanemizde hedeflenen süre açısından standartlara uygun ve başarılı bir şekilde uygulandığını göstermektedir. Sağkalım oranlarına bakıldığında ise 19 hastaya KPR uygulandı ve bu hastaların 16'sında resüsitasyona yanıt alındı (\%84.2). Hastalar yoğun bakım ünitemize transfer edildi, ancak 3 hasta yoğun bakım izleminde kaybedildi. KPR uygulanan hastaların \%68.4'ü hastaneden taburcu edildi.

Erişkinlerde mavi kod çağrı sistemi ile KPR uygulanan hastalarda en sık nedenin kardiyak nedenler olduğu belirlenmiştir ${ }^{(13,14)}$. Çocuk hastalarda ise solunum sistemi ile ilgili sorunlara erişkinlere göre daha sık rastlanmaktadır, bu nedenle mavi kod endikasyonları erișkinlerden farklılık gösterir. Çalıșmamızda, mavi kod çağrısı yapılan 19 hastada kardiyopulmoner arrest, 11 hastada yalnızca solunum arresti saptandı. Kardiyopulmoner arrestlerin en sık nedenleri ise konjenital kalp hastalığı ve hipoksik solunum yetmezliğiydi.

Mavi kodun esas endikasyonu kardiyopulmoner arrest olmasına rağmen, çalışmamızda da görüldüğü gibi hastaların yalnızca \%42.8'inde kardiyopulmoner veya pulmoner arrest vardı. Yapılan diğer çalışmalarda da uygunsuz çağrı oranının aynı olduğunu gördük $(13,15)$. Bunun nedeni arrestin tanımlanmasının her zaman kolay olmaması ve bildirim yapanların hızlı karar verme gerekliliğidir. Mavi kod çağrı sisteminde uygunsuz çağrı ve çağrı yerine ulaşmada yaşanan sıkıntılar verilen eğitimlerle azalmaktadır ${ }^{(13)}$. Hastane içindeki tüm personele verilen hizmet içi eğitimlerin artması ile beraber uygunsuz çağrı oranın azalacağını ve mavi kod sisteminin daha doğru ve etkin çalışacağını düşünmekteyiz.

Genel durumu kötüleşen hastayı erken fark edebilmek, arresti oluşmadan önleyerek sağ kalımı arttırmak esas hedef olmalıdır. Bunun için hastanın vital bulgularının değerlendirildiği ve buna bağlı bir skorlamanın oluşturulduğu erken uyarı sistemleri kullanılmaktadır. Bu sistem ile vital bulgular bozulmaya başladığında erken uyarı sistemi aktif hale gelir, arrest gelişmeden önce hastadaki klinik kötüleşme fark edilir ve gerekli müdahalenin yapılması sağlanmış olur. Erken uyarı sisteminin arrestleri önlediği ve sağkalımı arttırdığı gösterilmiştir ${ }^{(16)}$. Erken uyarı sistemi ve mavi kod uygulaması birbirlerini tamamlayan uygulamalardır ve birlikte kullanılmaları gerekmektedir. Hastanemizde yatan hastalar için aktif olarak kullanılan bir erken uyarı sistemi bulunmaktadır. Çalışmamızda gösterdiğimiz yüksek sağkalım oranlarının bu 2 sistemi birlikte kullanılıyor olmamızdan kaynaklandığını düşünmekteyiz.

Günümüzde kullanılan bildirim sistemleri çağrı cihazı, doğrudan telefon ile bildirim ve anons sistemidir. Hastanemizde anons ile bildirim sistemi kullanılmaktadır. Çağrı cihazı ve anons ile yapılan bildirimlerin daha hızı ve güvenli olduğu gösterilmiştir ${ }^{(3)}$.

Çağrıya ulaşma süresini etkileyen bir diğer faktör üst katlara ulaşımda yaşanan sorunlardır. Çağrının verildiği alana hızlı ulaşımı sağlayacak yapısal düzenlemelerin (mavi kod asansörü) sağlanmış olması önemlidir. Hastanemizde mavi kod çağrısı sırasında ekibe ve hastaya ayrılmış olan ayrı bir asansör bulunmaktadır. Bu sistemin çağrı yerine ulaşım süresini kısalttığını düşünüyoruz.

Mavi kod uygulaması hastanenin bütün alanını kapsar, sistemin sürekliliğinin sağlanması önemlidir. Mavi 
kod çağrılarının \%35.7'si mesai saatleri dışında gerçekleşmiştir. Bu nedenle mesai saatleri dışında nöbetçi ekibin bilinçlendirilmesi ve mavi kod ekibinin hazır bulundurulması önemlidir, uygulama 24 saat sürekli olarak devam etmelidir.

Sonuç olarak, mavi kod uygulaması hasta yaşam riski ve güvenliği açısından önemli bir standarttır. Ayrıca hastanelerin kalite düzeyini belirlemede kullanılan ölçütlerden biridir. Mavi kod ekibinde etkin ve alanından deneyimli uzmanların olması, hastane içi eğitimlere gereken önemin verilmesi ve sağlık tesisinin büyüklügüne göre mavi kod ekip sayılarının arttırılması hastane içi sağ kalımı arttırır. İnsan odaklı hataların minimalize edildiği subjektif değerlendirmeye dayalı erken uyarı sistemlerinin kullanılması arrest gelişmeden önce gerekli müdahalelerin yapılmasını sağlayarak mortalitenin azalmasına katkıda bulunur.

Mavi kod uygulaması ile ilgili az sayıda bilimsel yayın yapılmışır. Çocuk hasta kayıtlarının ayrı olarak değerlendirildiği çalışmaya rastlanmamıştır. Uygulamanın başarısının ve uzun dönem sağkalım ve taburculuk oranlarının belirlenmesi için daha kapsamlı araştırmalara gereksinim vardır.

Etik Kurul Onayı: Acıbadem Mehmet Ali Aydınlar Üniversitesi Tıbbi Araştırmalar Değerlendirme Etik Kurul onayı alınmıştır (2019-18/5).

Çıkar Çatışması: Yok

Finansal Destek: Alınmamıştır

Ethics Committee Approval: Acıbadem Mehmet Ali Aydınlar University Medical Research Evaluation Ethics Committee approval was obtained (2019-18/5).

Conflict of Interest: None

Funding: None

\section{KAYNAKLAR}

1. Resmi Gazete (2011). Sağlık Bakanlığı, Hasta ve Çalışan Güvenliğinin Sağlanmasına Dair Yönetmelik, R.G:06/04/2011, sayı: 27897.

2. İncesu E. Hayata dönüşün adı "mavi kod" seydişehir devlet hastanesi mavi kod birimine yapılan bildirim raporlarının retrospektif olarak değerlendirilmesi. Usaysad Derg. 2018;4:26-39.

3. Baskett PJ, Nolan JP, Handley A, Soar J, Biarent D,
Rishmond S. Europoen resuscitation council. Europoen resuscitation council guidleines for resuscitation 2005. Section 9. principles of training in resuscitation. Resusucitation. 2005;67:181-9. https://doi.org/10.1016/j.resuscitation.2005.10.006

4. Eisenberg MS, Bergner L, Hallstrom A. Cardiac resuscitation in the community. Importance of rapid provision and implications for program planning. JAMA. 1979;241:1905-7. https://doi.org/10.1001/jama.1979.03290440027022

5. Bal A, Memiş R, Kılıç H, ve ark. Mavi Kod Bildirimlerinin Değerlendirilmesi. II. Uluslararası Sağlıkta Performans ve Kalite Kongresi Bildiriler Kitabı, Sağlık Bakanlığı, Ankara. 2010;772:608-13.

6. Özütürk B, Muhammedoğlu N, Dal E, Çalışkan B. Mavi Kod Uygulama Sonuçlarının Değerlendirilmesi. Med Bull Haseki. 2015;53:204-8. https://doi.org/10.4274/haseki.2276

7. Mohnle P, Huge V, Polasek J, et al. Survival afer cardiac arrest and changing task profile of the cardiac arrest team in a tertiary carecenter. Scientific World Journal. 2012; 2012: 294512. https://doi.org/10.1100/2012/294512

8. Yılmaz Taşkın F, Konaşoğlu Sözen H, Karahallı E. Mavi kod bildirimleri, Süreyyapaşa Göğüs Hastalıkları ve Gögüs Cerrahisi Eğitim ve Araştırma Hastanesi Örneği. III. Uluslararası Sağııkta Performans ve kalite kongresi Bildirileri Kitabı. Sağlık Bakanlığı, Ankara, 2011; 869: 691-7.

9. Murat E, Toprak S, Doğan DB, Mordoğan F. Hasta güvenliğinde mavi kod uygulama sonuçlarının değerlendirilmesi. Medicine Science. 2014;3:1002-12. https://doi.org/10.5455/medscience.2013.02.8102

10. Esen O, Esen HK, Öncül S, Gaygusuz EA, Yılmaz M, Bayram E. Eğitim ve araştırma hastanesinde mavi kod uygulaması ve sonuçlarının değerlendirilmesi. J Kartal Tr. 2016;27:57-61.

11. Koltka $N$, Çelik $M$, Yalman A, Süren $M$, Öztekin F. Kardiyopulmoner resüsitasyonun başarısına etkisi olan faktörler. Türk Anes Rean Der Dergisi. 2008;36:366-72.

12. Canural R, Gökalp N, Yıldırım K, ve ark. Sağlık Hizmetlerinde Hasta Güvenliği: Mavi Kod Uygulaması Uluslararası Sağlıkta Performans ve Kalite Kongresi Bildirileri Kitabı. Sağlık Bakanlığı, Ankara, 2009;772:52540.

13. Gürmen ES, Demir B. Bir üniversite hastanesindeki mavi kod çağrı sisteminin uygunluğunun ve sonlanımının değerlendirilmesi. Van Tıp Derg. 2019;26:353-7.

14. Zheng ZJ, Croft JB, Giles WH, Mensah GA. Sudden cardiac death in the united states, 1989 to 1998. Circulation. 2001;104:2158-63. https://doi.org/10.1161/hc4301.098254

15. Türkyılmaz EU, Güzey NA. Bir kadın hastalıkları ve doğum hastanesinde mavi kod verilerinin retrospektif analizi. Jinekoloji - Obstetrik ve Neonatoloji Tıp Dergisi. 2019;2:89-92.

16. Nishijima I, Oyadomari S, Maedomari S, Toma R, Igei C, Kobata S. Use of a modified early warning score system to reduce the rate of in-hospital cardiac arrest. J Intensive Care. 2016;4:12. https://doi.org/10.1186/s40560-016-0134-7 